University of Nebraska - Lincoln

DigitalCommons@University of Nebraska - Lincoln

Publications, Agencies and Staff of the U.S.

Department of Commerce

U.S. Department of Commerce

2009

Genetic and Evolutionary Considerations in Fishery Management:

Research Needs for the Future

Robin Waples

NOAA, robin.waples@noaa.gov

Kerry A. Naish

University of Washington - Seattle Campus

Follow this and additional works at: https://digitalcommons.unl.edu/usdeptcommercepub

Waples, Robin and Naish, Kerry A., "Genetic and Evolutionary Considerations in Fishery Management: Research Needs for the Future" (2009). Publications, Agencies and Staff of the U.S. Department of Commerce. 457.

https://digitalcommons.unl.edu/usdeptcommercepub/457

This Article is brought to you for free and open access by the U.S. Department of Commerce at DigitalCommons@University of Nebraska - Lincoln. It has been accepted for inclusion in Publications, Agencies and Staff of the U.S. Department of Commerce by an authorized administrator of DigitalCommons@University of Nebraska - Lincoln. 


\title{
Chapter 23 \\ Genetic and Evolutionary Considerations in Fishery Management: Research Needs for the Future
}

\author{
Robin S. Waples and Kerry A. Naish
}

\begin{abstract}
Genetic methods have become indispensable for sound fishery management and will become even more so in the twenty-first century. Selectively neutral genetic markers are widely used in stock identification, mixed-stock fishery analysis, monitoring levels of genetic diversity within populations and levels of connectivity among populations, and for a range of other applications. We expect that future research will continue to provide incremental improvements in the number and type of genetic markers available, as well as in the methods for data analysis and the necessary computational resources. Topics that will merit special consideration include: (1) developing a better understanding of the various flavors of demographic independence and how genetic markers can provide relevant insights; (2) more powerful ways to deal with the low signal-to-noise ratio of population differentiation found in many marine species (the signal of genetic differences is small compared to various sources of random noise); (3) better integration of genetic information, biological information, and information about physical features of the habitat to provide a fuller picture of dynamic marine ecosystems; (4) whether the tiny effective size to census size ratios reported for some marine species are accurate, and if so what this means for conservation of large marine populations. In contrast to the situation with neutral genetic markers, evolutionary changes involving traits related to fitness have only recently attracted much attention in fishery management. In general, any changes to marine ecosystems alter the selective regimes that component species experience and hence can be expected to produce an evolutionary response. Three general topics are particularly important in this regard: harvest, artificial propagation, and climate change. One key challenge is to disentangle the effects of genetics versus environment in determining observed patterns of phenotypic change. Quantitative genetic and molecular genetic approaches can accomplish this, and our capabilities for examining functional parts of the genome are rapidly expanding. However, these methods are logistically challenging and resource-intensive, so in the near future will be feasible
\end{abstract}

R.S. Waples $(\bowtie)$

Northwest Fisheries Science Center, 2725 Montlake Blvd. East, Seattle, WA 98112, USA

e-mail: robin.waples@noaa.gov

K.A. Naish

School of Aquatic and Fishery Sciences, University of Washington, Seattle, WA 98195, USA 
for only a fraction of the species of interest to fishery management. Therefore, in the short term, inferences about evolutionary changes in marine species will have to draw on information for model species and other better-studied aquatic organisms.

Keywords Climate change - effective population size $\cdot$ genetic markers $\cdot$ harvest hatcheries · mixed-stock fisheries · stock identification

\subsection{Introduction}

The historical approach to fishery management was characterized by independent assessments for each species, but two major developments in the last half of the twentieth century substantially modified this paradigm. First, the gradual recognition that most species are composed of multiple independent populations or stocks, and subsequent refinement of the stock concept (Simon and Larkin 1972; Ihssen et al. 1981; Waldman 2005), led to a greater appreciation of the importance of genetic considerations in conservation and management (e.g., Ryman and Utter 1987). Fishery managers are now routinely aware of, if not necessarily expert in, the importance of conserving fitness and genetic diversity within and among populations. Second, and more recently, the concept of "ecosystem management" has been increasingly adopted in fishery and conservation applications (Mooney 1998; Lubchenco et al. 2003). As a result, stock assessments often include evaluations of effects of management actions on marine food webs, interspecific interactions (competition, predation), and community structure.

Although integration of ecosystem considerations represents an advance over historical, one-dimensional approach to stock assessments, virtually all evaluations conducted under this framework have focused exclusively on ecological factors. In contrast, evolutionary considerations of anthropogenic changes to aquatic ecosystems have received little attention. This is a serious omission, because any changes to aquatic ecosystems will also change selective regimes experienced by component species, and we can expect evolution (genetic change over time) to occur as a result. Furthermore, evolutionary changes are an important concern for fishery management. Not only can these changes affect productivity and sustainability of living natural resources; they also are generally irreversible on human time frames, if at all. Irreversible changes are a particular concern under another major advancement in natural resource management over the past decade - increasing application of the precautionary principle (articulated in the 1992 Rio Declaration, Anonymous 1992; Restropo 1999). The essence of the precautionary principle is to guide management toward actions that will not cause irreversible harm. Because biological systems are complex, it is often difficult to predict with certainty the consequences of any proposed action. Application of the precautionary principle involves shifting the burden of proof from asking, "Is there convincing evidence that the proposed action will cause irreparable harm?" to "Is there convincing evidence that the proposed action will not cause irreparable harm?" Answering the last question in 
a comprehensive way requires consideration of evolutionary as well as ecological consequences of proposed management actions.

In this chapter, we consider research that is needed to fully integrate genetic and evolutionary considerations into twenty-first century fishery management (see Waples et al. 2008 for a discussion of organizational, conceptual, and technical barriers that have hampered full use of genetic data in fishery management). For some well-established, genetically based programs, such as stock identification and mixed-stock fishery analysis, these future research needs are primarily incremental improvements to existing technologies and analyses. Evaluating the consequences of evolutionary changes in human-altered ecosystems will be more challenging, as this topic has been relatively neglected. Here, we focus on three major types of anthropogenic changes that can be expected to elicit a profound evolutionary response in natural populations: selective harvest, artificial propagation, and climate change.

Genetically based methods have a wide range of additional applications to fishery management, even though the problems they address are not necessarily evolutionary in nature. Although a full treatment of this topic is beyond the scope of what we can cover in this chapter, we expect these applications to be increasingly important in the future. Examples include forensics and enforcement (Baker et al. 2007), monitoring the status of individuals (von Schalburg et al. 2005; Purcell et al. 2006), monitoring the health of marine ecosystems (Niemi et al. 2004; Suttle 2005), and parentage analysis and the elucidation of mating systems (Emery et al. 2001; Avise et al. 2002).

\section{2 "Traditional" Applications Using Molecular Genetic Markers}

In this section we consider what might be called "traditional" applications of genetic markers to fishery management, which date back at least to the 1950s. The primary management issues addressed by these methods have been stock identification and population structure, analysis of mixed-stock harvests, and assessments of levels of genetic variation within populations. In the future, all of these approaches will benefit from incremental improvements in the number and quality of molecular markers, as well as continued refinements in methods of data analysis. Specific considerations are outlined below.

\subsubsection{Stock Identification and Population Structure}

Because stock assessments typically assume that the unit under consideration is demographically homogeneous, stock identification is a necessary precursor to scientifically based fishery management (see Cadrin et al. 2005 for a review). The revelation that protein electrophoresis could uncover abundant genetic variation in natural populations led to an explosion of studies on natural populations of fish 
(reviewed by Ward et al. 1994). More recently, mitochondrial DNA (mtDNA) and nuclear DNA (primarily microsatellites and single nucleotide polymorphisms [SNPs]) methods have seen widespread application (Carvalho and Hauser 1998; DeYoung and Honeycutt 2005; Ward 2006).

Genetic methods have provided a great deal of insight into stock structure in marine species, but they have some inherent limitations for drawing inferences about stock structure. This is because levels of migration or gene flow that can be most effectively studied using genetic techniques are low compared to the levels that are typically of interest in stock identification (Carvalho and Hauser 1994; Waples 1998; Waples and Gaggiotti 2006). For example, stock assessments generally assume demographic independence of the units under consideration, which means that population dynamics are driven more by local births and deaths than by immigration. The transition from demographic independence to dependence has not been rigorously studied, but available information suggests it occurs in the range of $m=0.1$ (Hastings 1993; McElhany et al. 2000 ) - that is, if the rate of exchange of individuals among populations $(m)$ is greater than about $10 \%$, the populations tend to have correlated demographic trajectories. This poses a challenge for use of genetic markers, since $10 \%$ migration represents a very high rate of gene flow in evolutionary terms. As a consequence, genetic markers typically have low statistical power to distinguish between migration rates (say $5 \%$ vs $20 \%$ ) that could have very different management implications.

In the future, more work is needed in several areas. First, it is important to clarify the management question(s) more precisely than simply calling for "stock identification." Just as there is no single, universally accepted definition of "species" or "subspecies," there is no single biological definition of "stock." Rather, the appropriate concept of "stock" or "population" should be related to the management goals one is trying to achieve (Waples and Gaggiotti 2006). This point can be illustrated by considering three federal laws in the United States that mandate conservation of subspecific units of marine species: the Marine Mammal Protection Act (MMPA), the Endangered Species Act (ESA), and the Magnuson-Stevens Fisheries Conservation and Management Act (MSA). The MMPA defines a biological stock as a "group of animals in common spatial arrangement that interbreeds when mature." Although this definition is rather vague, the stipulation of the MMPA to avoid localized depletions has led to identification of stocks on a fine geographic scale in many instances. Under the SFA, the term "stock of fish" means a "species, subspecies, geographical grouping, or other category of fish capable of management as a unit." A key driving force in implementation of the SFA is the requirement to rebuild overfished populations to sustainable levels within 10 years. Under this management framework, therefore, demographic linkages with another stock would have to be very strong to experience any significant rescue effect over this short time period. The ESA allows listing of subspecies and "distinct population segments" (DPSs) of vertebrates, as well as full species. In Pacific salmon (Oncorhynchus spp.) status determinations under the ESA, most DPSs have included relatively large geographic areas and a substantial number ( 20-30) of component stocks. To provide a framework for ESA recovery planning for salmon, McElhany et al. (2000) developed the concept of viable salmonid populations (VSP) and defined a demographically independent population (within a DPS) as one for which immigration from other populations 
does not appreciably affect extinction risk over a 100 -year time period. Thus, all these statutes require consideration of population linkages, but each entails a different concept of demographic independence and a different standard for assessing how strong the isolation must be to warrant recognition of separate management units.

Second, it is a curious fact that what would appear to be a central question in population ecology (how much migration among populations is required before they behave as a coupled system?) has received relatively little attention. The Hastings (1993) study, which is the only published paper that directly addresses this topic, provides only a rough guide for certain definitions of dependence/independence. More rigorous evaluations are needed of the levels of migration that lead to various flavors of demographic dependence/independence.

Third, the future will see incremental increases in the power of genetic markers to provide useful information for high-gene flow species. With arbitrarily large numbers of genetic markers, in theory it is possible to resolve arbitrarily small genetic differences among populations. However, the increases in power will be asymptotic, so at some point the marginal benefits of adding additional markers will decline sharply. Furthermore, along with greatly increased power comes greatly increased sensitivity of the results to data artifacts (Waples 1998). This topic has only recently been treated seriously in the scientific literature (Bonin et al. 2004; Pompanon et al. 2005). In the future, it will be increasingly important to rigorously assess data quality, quantify rates of genotyping errors, refine methods to keep error rates as low as possible, and evaluate performance of genetic methods for data that (inevitably) include some low level of errors.

Fourth, when the signal-to-noise ratio is low, as it often is in studying genetic structure of marine species, it is also important to pay particular attention to experimental design, because small departures from random sampling can be mistaken for a biological signal (Waples 1998). In addition, dynamic and chaotic processes in the ocean that govern dispersal and survival of larvae often produce patterns of genetic variation that are not temporally stable and are difficult to interpret in terms of population structure (Johnson and Wernham 1999; Pujolar et al. 2006; Selkoe et al. 2006). These challenges mean that adequate spatial and temporal replication is generally required to develop rigorous information about population structure in marine species.

Fifth, recent advances in physical oceanography and remote sensing open up exciting new possibilities to more fully integrate inferences about connectivity based on genetic markers with life-history traits and the dynamic nature of the marine environment (e.g., Galindo et al. 2006; Selkoe et al. 2008).

\subsubsection{Mixed-Stock Harvests and Individual Assignments}

Mixed-stock harvests represent one of the most pervasive and challenging problems facing fishery managers. Naturally occurring genetic marks have some inherent advantages for the analysis of mixed-stock fisheries compared to more traditional methods: they do not require large efforts to manually mark individuals every generation; genetic markers are temporally stable compared to some other stock identification methods 
(such as scale pattern analysis) that need to be surveyed in baseline populations every year (Cadrin et al. 2005); they can provide information for natural populations as well as cultured ones. A maximum-likelihood method for genetic stock identification (GSI) was developed in the late 1970s that estimates the stock composition of a mixed harvest, based on genetic samples from populations that potentially contribute to the mixture and from the mixture itself. Subsequently, the basic approach has been modified a number of times (reviewed by Pella and Milner 1987; Manel et al. 2005) and applied broadly to a wide range of species and geographic areas (reviewed by Shaklee et al. 1999). Challenges for the future include the following:

- Increases in the number of genetic markers will improve overall power but will make the assumption that the markers are independent increasingly untenable. Studies to elucidate the physical linkages among markers will be important to maximize their usefulness. If properly accounted for, physical linkages can actually improve power of genetic markers to resolve mixtures of gene pools (Falush et al. 2003; Verardi et al. 2006).

- Current methods for assessing the power of GSI to resolve mixtures of specific natural populations are biased towards an overly optimistic assessment of power (Anderson et al. 2008). Improvements are needed in this area, not only in assessing uncertainty in stock origin of sampled fish, but also in incorporating uncertainty in sampling from the fishery into an overall assessment of precision and accuracy.

- Increasingly, conservation concerns focus on stocks that are minor contributors to fisheries but can be the triggers for harvest management decisions. For example, in the analysis of a large fishery, it can be crucial to determine whether a particular stock is totally absent, or contributes a small fraction (say $<1 \%$ ) of the catch. This is a very challenging statistical problem that requires advances in two areas: (1) power to distinguish stock-of-origin of fish from genetically similar stocks, and (2) power to draw reliable inferences about minor contributors from relatively small samples from a large fishery.

- Although genetic markers are relatively stable over time, gene frequencies change stochastically in all finite populations, and evaluations of the effects of these changes on GSI estimates have been rather limited (Waples 1990). This issue will be increasingly important as increased power allows resolution of ever-more-closely related populations.

- The standard GSI model is referred to as "constrained maximum likelihood" because it assumes that all stocks in the mixture are represented in the baseline. An unconstrained model, which allowed for the possibility that unsampled populations might contribute to the mixture, was proposed by Smouse et al. (1990), but only recently have statistical refinements, development of more variable genetic markers, and vastly increased computational power combined to make this feasible to implement for large-scale management problems. The recent increased interest in genetic clustering methods (e.g., Pritchard et al. 2000; Pella and Masuda 2006) holds promise for significant advances in this area in the future.

- A management problem related to GSI involves identification of stock-of-origin for individuals, using genetic "assignment tests." This can be important, for example, in 
forensic applications (where it might be necessary to determine whether a particular individual was taken from a protected population), or to screen individuals in a broodstock program to ensure genetic purity (Olsen et al. 2000). These applications involve consideration of trade-offs between Type I and Type II error rates, and this topic needs further development (Paetkau et al. 2004; Manel et al. 2005).

\subsubsection{Levels of Genetic Variation}

Genetic variation within populations provides the raw material for evolution and the resilience for populations to respond to future environmental (and anthropogenic) challenges. Studies of marine and anadromous populations have provided a great deal of information about natural levels of genetic variability, primarily at gene loci thought to be selectively neutral. Two related topics will be important to resolve in the future, both involving the effective size $\left(N_{\mathrm{e}}\right)$ of natural populations. $N_{\mathrm{e}}$, which determines the rate of evolutionary change, is generally smaller than the census size $(N)$.

"Bottlenecks" in large populations: an overlooked risk? - Conventional wisdom holds that most marine species are largely immune to genetic effects of bottlenecks, because after a population "crash" a widespread marine species still might have very large numbers $\left(>10^{6}\right)$ of individuals. It is true that dramatic declines that still left a large $N_{\mathrm{e}}$ would have essentially no effect on the rate of allele frequency change (which is already negligible in large populations), and it is also true that such declines would not necessarily have an appreciable affect on the most commonly used measure of genetic variability, average heterozygosity $(H)$. Population genetics theory tells us that, at equilibrium, the expected value of $H$ for selectively neutral alleles is given by

$$
H=1-1 /\left(1+4 N_{e} \mu\right)
$$

where $\mu$ is the per-generation mutation rate to neutral alleles (Kimura and Crow 1964). Table 23.1 shows that for $\mu$ in the range $10^{-3}-10^{-5}$ (as might apply, e.g., to

Table 23.1 At equilibrium, the amount of selectively neutral genetic diversity in a closed population is a function of effective population size and mutation rate $(\mu)$. The number of alleles is much more sensitive than heterozygosity to "crashes" in large populations (Based on Kimura and Crow 1964)

Effective population size

\begin{tabular}{llll}
\hline (A) Heterozygosity & & & \\
& $10^{5}$ & $10^{7}$ & $10^{9}$ \\
$\mu=0.001$ & 0.998 & $\sim 1.0$ & $\sim 1.0$ \\
$\mu=0.00001$ & 0.800 & 0.998 & $\sim 1.0$ \\
(B) Effective number of alleles & & & \\
& $10^{5}$ & $10^{7}$ & $10^{9}$ \\
$\mu=0.001$ & 400 & 40,000 & $4,000,000$ \\
$\mu=0.00001$ & 5 & 400 & 40,000 \\
\hline
\end{tabular}


microsatellites), $H$ is nearly 1 for very large populations and still very high if $N_{\mathrm{e}}$ drops to $10^{5}$. In contrast, the effective number of alleles that can be maintained in a population $(n=1 /(1-H)$; Kimura and Crow 1964) is nearly a linear function of $N_{\mathrm{e}}$ for this range of $N_{\mathrm{e}}$ and $\mu$ values. Thus, whereas a population that declines from $N_{\mathrm{e}}=10^{9}$ to $10^{5}$ (four orders of magnitude) experiences very little loss of heterozygosity, the same population can be expected to lose the vast majority of alleles, most of which occur at very low frequency (Ryman et al. 1995). So what? What happens if a population loses a large fraction of its standing crop of rare alleles, as long as it maintains adequate levels of heterozygosity?

One of the challenges in the future will be to answer this question. Although immediate consequences for the population might not be severe, longer-term prospects are less certain. Rare alleles lost during a population crash could take a very long time to regenerate by mutation. Certain genes, such as those associated with the major histocompatibility complex (MHC), are extremely variable in vertebrates. These loci play crucial roles in immune response, and the high levels of variability appear to be maintained by natural selection (Bernatchez and Landry 2003; Garrigan and Hedrick 2003). If the ratio $N_{\mathrm{e}} / N$ is very low in some marine species (see Section 23.3), these "bottleneck" effects on genetic diversity might be apparent at much higher population sizes than has previously been appreciated.

The $N_{\mathrm{e}} / N$ ratio in marine species: can we believe the tiny estimates? - At least a half-dozen published studies of $N_{\mathrm{e}}$ in marine species have estimated tiny ratios of effective size to census size $\left(N_{\mathrm{e}} / N \sim 10^{-3}-10^{-5}\right.$; Turner et al. 2002; Hauser et al. 2002; Hauser and Carvalho 2008). These estimates contrast sharply with theoretical considerations that suggest the $N_{\mathrm{e}} / N$ ratio should only rarely be less than 0.5 (Nunney 1993) and empirical data for a wide range of species, for which most estimates fall in the range of 0.1-0.5 (Frankham 1995). Hedgecock (1994) proposed a possible mechanism (sweepstakes recruitment) to explain low $N_{\mathrm{e}} / N$ ratios in marine species. According to this hypothesis, chance events in the chaotic and patchy marine environment cause most families to produce no offspring at all that survive to reproduce; instead, the next generation is derived from the relatively few sweepstakes winners, whose offspring happen to arrive in the right places at the right times to promote feeding, predator avoidance, dispersal, and other vital life-cycle events. If this hypothesis is generally true, and as a result $N_{\mathrm{e}} / N$ ratios in many marine species are orders of magnitude lower than typically found for other organisms, it means that serious genetic concerns might apply to populations that would otherwise appear to be immune. For example, Hauser et al. (2002) estimated that for the New Zealand snapper (Pagrus auratus) in Tasman Bay, harmonic mean $N$ for the period 1950-1998 was several million fish but $\hat{N}_{e}$ was only 176 - over four orders of magnitude smaller. A population with $N_{\mathrm{e}}>10^{6}$ experiences essentially no genetic drift, while a population with $N_{\mathrm{e}}=176$ is in the range where random genetic processes are a real conservation concern. It is therefore important to consider the question, "Are the tiny $N_{\mathrm{e}} / N$ ratios estimated for some marine species reliable?"

All of the tiny $N_{\mathrm{e}} / N$ estimates are based on genetic estimates of $N_{\mathrm{e}}$ and demographic estimates of $N$. Although estimates of $N$ are often highly uncertain, it seems unlikely that errors in estimating population abundance could be large enough to explain this 
discrepancy. Genetically based estimates of $N_{\mathrm{e}}$ typically also have a high stochastic variance, and the distribution is very skewed toward high values because of the inverse relationship between $N_{\mathrm{e}}$ and the genetic quantities being measured. As a result, the upper bounds of confidence limits (CIs) to $\hat{N}_{\mathrm{e}}$ are often very high. For example, for many of the point estimates of $N_{\mathrm{e}}$ reported by Hauser et al. (2002), the upper bounds of the CI included infinity, even when the point estimate was in the range of $10^{2}-10^{3}$. Issues that need more attention in the future include the following:

- Effects of small departures from random sampling

- Effects of genotyping errors

- Small biases in $N_{\mathrm{e}}$ estimators that might become large under certain conditions

- Effects of migration and selection

- Optimal ways to combine information from multiple methods for estimating $N_{e}$

\subsection{Evolutionary Changes in Aquatic Populations}

The applications of genetic markers discussed above all take advantage of natural evolutionary processes that have occurred among and within populations and which produce a signal that can help inform fishery management. Here we consider evolutionary changes to natural populations that are influenced by anthropogenic factors (see Smith and Bernatchez 2008 for extensive treatment of this general topic). Whereas the approaches discussed above generally utilize neutral markers, the changes considered here involve traits directly related to fitness. Most fitness traits are coded by a number of genes - known as quantitative trait loci (QTL) - that interact with each other and with the environment to produce a range of phenotypes. In this section, we first discuss the potential for (and some general limitations of) the study of quantitative traits in aquatic populations, and we conclude by focusing in more detail on three specific topics: selective fisheries, artificial propagation, and climate change.

\subsubsection{Establishing the Genetic Basis of Trait Variation}

A difficult challenge is to discriminate evolutionary (genetic) changes from phenotypic plasticity, which occurs when the same genotype exhibits different phenotypes in diverse environments (Naish and Hard 2008). The range of phenotypes a particular population exhibits under different environmental conditions is known as its norm of reaction (Pigliucci 2005). A population can respond plastically (without genetic change) to different environmental conditions by moving along its norm of reaction, or it can respond by evolving a different relationship between genotype and environment (i.e., by changing its norm of reaction). Figure 23.1 illustrates these points schematically, using hypothetical mean trait values for four populations across five different environments. Population 4 has a flat norm of reaction (no variation in trait value among environments) and hence no phenotypic plasticity. Populations 1 and 2 


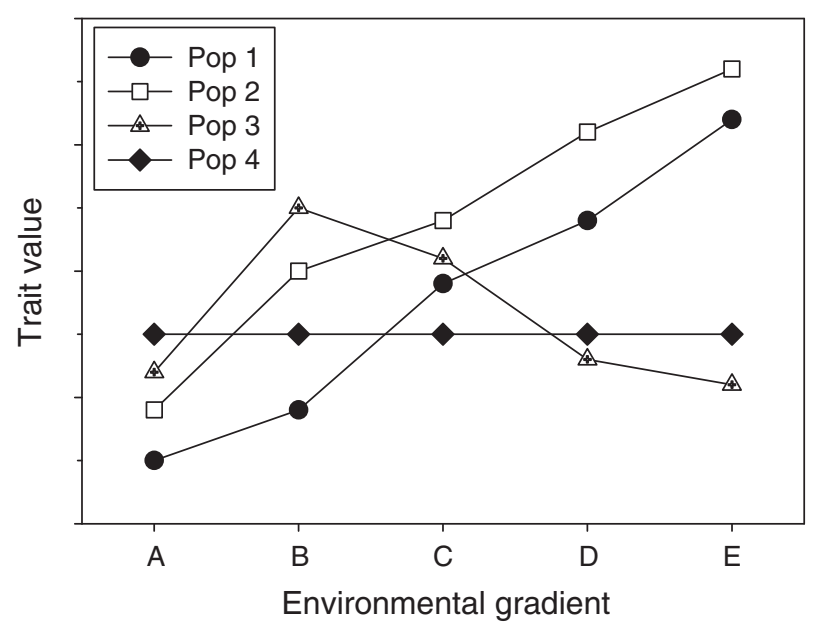

Fig. 23.1 Norms of reaction for four hypothetical populations across an environmental gradient. Datapoints are mean population trait values in each environment. See text for discussion

have roughly parallel norms of reaction, indicating considerable phenotypic plasticity. Population 3 shows a complex reaction norm, with a peak trait value in the middle of the environmental gradient. The different reaction norms imply genetically based adaptations to local environmental conditions in different populations. Populations 1-3 have considerable ability to respond to environmental change by modifying their phenotypes, but Population 4 does not. One possible response to environmental change of a population like Population 4 is to evolve a different norm of reaction to provide more opportunity for phenotypic plasticity.

Two general approaches are used to discriminate genetic and environmental effects on the phenotype. The first, particularly useful for detecting evidence of local adaptation, relies on reciprocal transplants or common garden rearing (Kawecki and Ebert 2004). Because environmental variation is controlled, differentiation between individuals or populations is assumed to be genetic. The second approach partitions the observed phenotypic variance of a fitness trait, $V_{\mathrm{p}}$, into the genetic $\left(V_{\mathrm{g}}\right)$ and environmental $\left(V_{\mathrm{e}}\right)$ variances $\left(V_{\mathrm{p}}=V_{\mathrm{g}}+V_{\mathrm{e}}\right)$ by studying the co-inheritance of traits between relatives. If one can estimate the heritability ( $h^{2}$, the fraction of total trait variation that is due to additive genetic variance) and the strength of selection $S$ for a trait, the population response $R$ can be predicted from the breeder's equation $R=h^{2} S$ (Falconer and Mackay 1996). However, both approaches have limited applications to natural populations. Transplant experiments are logistically challenging, even if a permit could be obtained, and common garden experiments typically require at least two generations of breeding to reduce maternal effects. Estimating $h^{2}$ in fitness-related traits requires careful tracking of relatives in a common environment (Falconer and Mackay 1996), which is difficult in nature. As a consequence, estimates of heritability in fishes are dominated by production-related traits relevant to aquaculture (Gjedrem 2000). Improvements in methods of pedigree analysis using molecular markers have made it possible to 
study the inheritance of traits between relatives, which in turn has led to estimates of $h^{2}$ in some wild populations (Keller et al. 2001; Garant et al. 2003). Use of these methods to track rate, direction, and mode of selection in wild populations is promising, but will necessarily involve research over many generations.

It is becoming increasingly apparent that quantitative traits cannot be evaluated in isolation. For example, body size and growth rate typically affect other traits such as age at maturity, number of offspring, and survivorship. Evolution of correlated traits can be studied by evaluating changes in the genetic variance - covariance matrix (the G matrix; McGuigan 2006). Future research needs in this area are the generation of empirical measures of additive genetic variances and covariances of correlated traits in wild populations, which can then be used to parameterize models investigating the likely consequences of anthropogenic influences on fish populations.

\subsubsection{Molecular Approaches to the Study of Adaptive Traits}

The many logistical challenges associated with traditional quantitative genetic methods have fostered interest in molecular approaches aimed at studying functionally important genetic variation, which is the raw material on which selection acts. If the genes underlying a quantitative trait can be identified, then a more mechanistic approach to predicting evolutionary responses can be developed. Efforts towards identifying this variation is most advanced in organisms whose genomes have been sequenced (e.g., humans (Akey et al. 2004), the fruit fly, Drosophila (Schlotterer et al. 2006), and the plant Arabidopsis (Mitchell-Olds and Schmitt 2006)). Most marine species will probably not be the target of sequencing efforts for many years, and even if sequences were generated, the task of identifying functionally important variation requires large-scale studies at the population level, across a significant number of individuals. Therefore, identifying this variation in non-model organisms (including most fish species) will require adapting the most promising results from model organisms.

Approaches for detecting adaptive genetic variation in non-model organisms can be broadly classified into "top-down" methods (which start with the phenotype and work downward to elucidate the underlying genetic factors) and "bottom-up" methods (which start with DNA polymorphisms and work upwards to the phenotype) (Fig. 23.2; see also Vasemagi and Primmer 2005).

Detection of quantitative trait loci $(Q T L)$ - An example of a top-down approach that has been rapidly expanding in fishes (Danzmann and Gharbi 2001) is the use of genome mapping to detect QTL underlying life-history traits. Genome mapping of QTL involves tracking the co-inheritance of markers and genes in pedigrees segregating for the fitness traits of interest. If trait genes and markers are inherited together, the latter can be used as proxies for the former. QTL mapping is dependent on populations that segregate for the trait of interest. Such populations are readily available in model organisms but are rare in marine species - even in aquaculture 


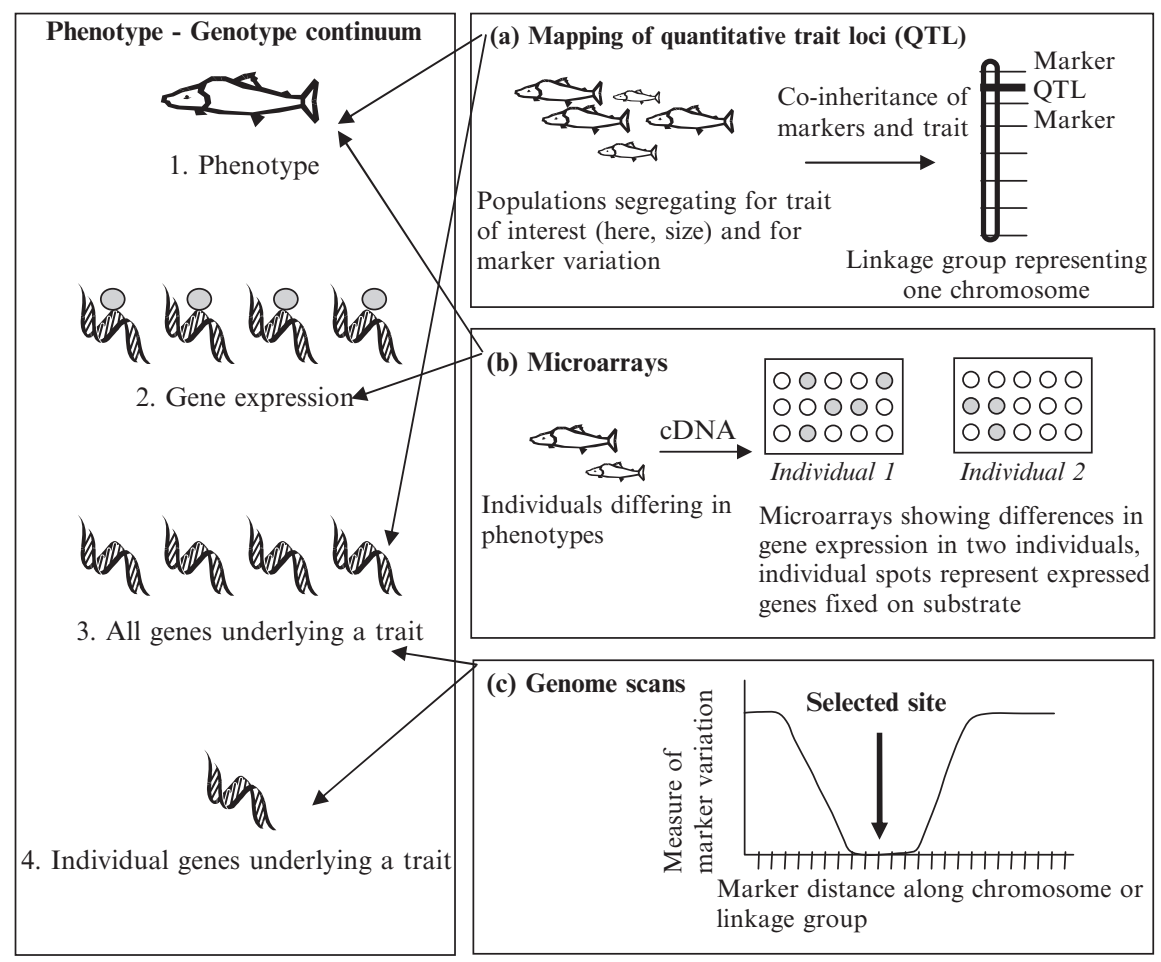

Fig. 23.2 Schematic illustrating methods for detecting functional genetic variation in non-model organisms whose genome sequences are unknown. Methods are initially aimed either at the top of the phenotype continuum (a and b), or at the bottom (c). Approaches correspond with those described in the text

populations that have been cultured for several generations. In the future, attention should be focused on creating and maintaining such experimental lines, or on performing informative crosses between populations that differ in life-history traits. Such efforts will be considerably enhanced by development of genome maps with sufficient marker coverage. One disadvantage of QTL studies is that markers found to be linked to QTL are only useful if recombination has not occurred between these two regions, so this approach is most useful for recently diverged populations (Lynch and Walsh 1998).

Microarrays and mapping of expression variation - Microarrays, which consist of many expressed or short DNA sequences spotted on chips or membranes (Stearns and Magwene 2003), represent a second type of top-down approach. Messenger RNA extracted from samples can be hybridized to these arrays to identify genes that are either up- or down-regulated under different conditions. Most microarray studies have focused on physiological or disease status rather than evolutionary considerations; however, Roberge et al. (2006) showed that a subset of genes in two aquaculture strains of Atlantic salmon of different origin have similar patterns of 
directional divergence from their progenitor wild strains, suggesting a generalized genetic response to the effects of domestication.

In a related approach that integrates QTL mapping and expression analyses (eQTL mapping; Schadt et al. 2005), individuals are assayed with microarrays and expression levels are treated as phenotypes and mapped to chromosome regions. In this way, gene regulation can be attributed to polymorphism in the gene itself (if segregation in expression levels map to the same position as the gene) or to other genomic regions controlling the transcription of a given gene (if the eQTL maps to another position), and interactions between genes in a pathway underlying a complex trait can be teased apart.

Microarray studies require careful experimental design. Differences in gene expression can arise from environmental as well as genetic variation, and extensive replication is necessary to accommodate environmental and life-history differences between test subjects. In addition, such experiments do not discriminate between partially and fully transcribed genes. At present microarray experiments are expensive to implement on a large scale, so technological improvements would be needed to allow implementation in large experiments. Such improvements would also require advances in complex analytical methods for the extensive datasets that would be generated.

Population genomics - Population genomics is a bottom-up approach that involves sampling the genome for polymorphisms that might help elucidate the dominant evolutionary processes affecting populations. If neutral markers are physically linked to genes under selection, the neutral markers will also be affected by selection (through a process known as hitchhiking), and their behavior will deviate from models of neutrality (Luikart et al. 2003; Storz 2005). The neutral markers thus can be used as proxies for selected regions to address a wide array of questions. The basic population genomics approach involves comparing divergence between two or more populations at a large number of marker loci, in a process known as a "genome scan." Genes whose behavior does not conform to a neutral model are subjected to additional tests to determine the type of selection involved. Inferences can be drawn about the population's demographic history (drift and gene flow) and weighed against the relative role of fitness and adaptation in determining population divergence.

Population genomic approaches are rapidly evolving (Goetz and MacKenzie 2008), and the statistical power to detect the existence and mode of selection is still unclear. A handful of theoretical studies have shown that the likelihood of detecting genomic regions under selection will depend on mutation rate of the marker, the recombination rate between that marker and the selected region, the time since divergence between the populations, the strength of selection, the sizes of the populations since divergence, and whether selection has acted upon new, or standing, variation within a population (Beaumont 2005; De Kovel 2006). Therefore, a strong research need exists for analytical approaches that will provide a realistic understanding of what can and cannot realistically be accomplished using population genomics. One additional disadvantage is that the exact link between the phenotype and the chromosome region under selection will not be known without 
further study. However, population genomics can help in targeting regions of the genomes that have played an important role in evolution for further characterization by sequencing.

\subsubsection{Selective Harvest}

Harvest management typically focuses on the numbers of fish captured or the harvest rate. However, any mortality imposed upon a population also has the potential to elicit an evolutionary response (genetic change) in the population if the mortality is selective (non-random) with respect to a genetically controlled trait. A wide range of traits might be subject to this type of selection, including size and age, migration timing, and behavior.

Size and age - Ricker's (1981, 1995) early work on this topic involved Pacific salmon, but more recently the potential evolutionary consequences of size-selective harvest for marine fish have attracted a good deal of attention. In a widely publicized example, Olsen et al. $(2004,2005)$ showed that in the decades prior to the collapse of cod (Gadus morhua) populations off Newfoundland and Labrador, a continual shift occurred toward maturation at an earlier age and smaller size. In an attempt to control for various confounding environmental factors, these cod studies focused on reaction norms for maturation and concluded that there was evidence for rapid fishery-induced evolution of maturation patterns. Because fecundity and gamete quality in cod (and other marine species) are positively correlated with size (Trippel 1998), the observed changes in life history substantially reduce productivity (and hence resilience) of the affected populations. Furthermore, evolution of early maturation at small size in response to selective take of larger fish can have long-lasting consequences for a population. Even if selective harvest is terminated, it might take a long period of time (perhaps much longer than the period of change driven by selective harvest) for the population to re-evolve traits consistent with high productivity. During this period, the population must repay the 'Darwinian debt' created by rapid evolution toward a new fitness peak in an altered environment (Walsh et al. 2006).

The approach used to identify fisheries-induced evolutionary change in cod ("probabilistic maturation reaction norms" [PMRNs]) recognizes the important effect of evolution on correlated traits (Grift et al. 2003). The approach is retrospective in nature and assumes that one correlated trait (age at maturity) is under genetic control, while the other (length at maturity) is environmentally influenced (Grift et al. 2003; Olsen et al. 2004). This assumption is controversial. Many quantitative genetic studies have shown that both traits are influenced by genetic variation and the environment, and some have shown that growth rate rather than size at age determines maturation (Morita and Fukuwaka 2006). Observed changes in the maturation schedule in cod were rapid following a fishery moratorium - faster than might be expected if evolution were occurring - suggesting that the changes in maturation reaction norms might have responded to shifting environmental condi- 
tions, rather than to genetic change (Law 2007). However, proponents of PMRNs have argued that the approach is valid as long as growth has an environmental component (Dieckmann and Heino 2007). It has also been pointed out that the twodimensional PMRN approach used in the cod example does not separate phenotypic plasticity from changes in maturation schedule, although a multidimensional approach might (Kraak 2007). The maturation reaction norm is only one of many traits that might respond to harvest selection (Law 2007), so there is a strong need to experimentally verify the PMRN approach across a wide range of harvested species and traits.

Migration timing - Diadromous fishes are legendary for their long migrations, but many marine species also make considerable geographic movements between feeding and breeding grounds, and these migration routes often provide key harvest opportunities. Harvest of migrating fish stocks has a strong potential to elicit an evolutionary response; unless the harvest rate (chance that an individual is captured) is constant over the entire migration, certain portions of the population will experience higher mortality than others. Furthermore, temporally selective harvest could affect other traits correlated with migration timing. For example, if harvest rates are higher in the first part of the migration, and if older, larger fish tend to migrate early, then this type of fishery would have the same consequences for age and size as one whose gear actively selected for large fish.

An empirical example from Pacific salmon illustrates how management strategies can have evolutionary consequences for migration timing. The Bristol Bay, Alaska, fishery for sockeye salmon has remained productive for over a century, in part because of strong safeguards to ensure that an adequate number of spawners reach the spawning grounds. One way to accomplish this is to keep harvest rates low until the escapement goals are reached, in which case the fishery actively selects against late-migrating fish. Quinn et al. (2007) found empirical evidence that over a 35-year period under this type of harvest regime, sockeye from the Egigik district have shifted toward an earlier migration timing - the type of response predicted by an evolutionary model, although environmental effects cannot be ruled out.

Behavior (catchability) - Harvests will also be selective if the probability that an individual is caught (its catchability) depends on its behavior (cautious vs curious; more vs less aggressive; preference for deep vs shallow habitat; strong vs weak diurnal vertical migrations; etc.). To the degree that such differences affect catchability and have an underlying genetic basis, they can be expected to produce an evolutionary response in the population. This topic has had little treatment in the literature, but an unpublished study over four generations in largemouth bass (Micropterus salmoides) showed a strong evolutionary response to selection for vulnerability to angling (Philipp et al. in press).

Research needs for the future - If (as will almost inevitably be the case) harvest rates are not uniform across all types of individuals in a population, and if the traits subject to selective harvest have at least in part a genetic basis, the key questions are not whether evolutionary change will occur, but rather the following: How large will these evolutionary changes be? What effect will these changes have on fishery yield and population viability? If selective harvest is terminated, can evolutionary 
changes be reversed, and if so, how long will it take? The following types of research can provide insight into these questions.

- Characterize the genetic basis of traits under selection (especially size, growth, age structure, and fertility), as well as the genetic correlations among traits.

- Measure the degree of selectivity of harvests, and monitor changes in life-history traits in exploited populations.

- Determine how to distribute fishing mortality over fish of different sizes (or other traits) to minimize selectivity.

- Evaluate how shaping fishery impacts (controlling time and location of harvests; gear types) affects harvest selectivity.

- Consider scaling harvest rate and selectivity to ocean/habitat productivity.

Integration of the $\mathbf{G}$ matrix into harvest models can contribute to an understanding of the evolutionary consequences of fishing (Law 2000) and the effects of measures taken to reduce these changes (Hard 2004). This approach can be parameterized using empirical measures of heritabilities, variances, and covariances derived for individual species. Further work in this area should seek to integrate these approaches into standard harvest and population viability models.

\subsubsection{Artificial Propagation}

Evolutionary consequences of fish culture on natural fish populations, especially for salmonids, have been extensively treated in the literature, and this topic will only briefly be summarized here. Interested readers can find more detailed treatments of these topics in Busack and Currens (1995), Waples and Drake (2004), Naylor et al. (2005), Ward (2006), Naish et al. (2008), and Fraser (2008). It is important to distinguish two general kinds of artificial propagation: (1) aquaculture, which involves raising individuals to market size in what are intended to be closed systems; and (2) sea ranching, which involves intentional release of individuals into the wild. Similarly, two general types of sea-ranching programs can be identified: those designed for harvest augmentation (which, like aquaculture programs, might produce societal benefits, but also entail risks to natural populations); and those designed for supplementation of natural populations (which therefore involve intentional integration of hatchery and natural production). Aquaculture and harvest augmentation programs provide little or no benefit to wild populations, but (in at least some circumstances) the risks can be contained within an acceptable level. Supplementation programs have the potential to (at least temporarily) improve the status of wild populations, but also can dramatically change the selective regimes they experience. Careful articulation and consideration of program goals is therefore necessary in evaluating the overall risks and benefits of artificial propagation.

The principle evolutionary changes that natural populations can experience directly or indirectly as a result of artificial propagation are loss of genetic diversity within and among populations and loss of fitness. A number of strategies can be used to help reduce genetic risks of artificial propagation (see references cited 
above), but certain facts must be realized at the outset and should be factored into management plans. First, evolutionary changes cannot be avoided in cultured populations. The whole raison d'etre of an artificial propagation program is to provide a benign environment to promote high survival. Dramatic changes in the mortality profile of a population cannot occur without attendant evolutionary changes; at best one can hope to minimize these changes. Second, it is not possible to simultaneously minimize all risks associated with artificial propagation; many of the risks are inversely correlated, such that reducing one inevitably increases another (Waples and Drake 2004). To take just one example, in supplementation or sea-ranching programs, releasing juveniles early helps to minimize the scope for selective changes due to culture and provides more opportunity for selection to act in the wild. However, early-release juveniles typically have lower survival (which might affect program goals), and releasing large numbers of early life-stage juveniles into the wild increases opportunities for competitive interactions with wild fish and also affects the selective regimes experienced by the wild population.

Although much of the literature on effects of cultured fish on natural populations involves salmonids, the number of marine species that are actively propagated is in the hundreds and rapidly increasing (Leber et al. 2004). Nearly half of all the fish consumed around the world are now farmed (FAO 2006), and expectations for future increases in marine protein production rely heavily on aquaculture. Recently, Woods Hole Oceanographic Institution convened a Marine Aquaculture Task Force to recommend standards and practices for US marine aquaculture to protect the health of marine ecosystems. If the recommendation of the Panel (Anonymous 2007) to shift culture toward local, native populations is followed, it would considerably alleviate concerns regarding spread of disease and invasive species. However, this change could also greatly increase opportunities for genetic interactions with wild populations, with uncertain consequences. Some research topics that will be important in the future include the following:

- What are the relative evolutionary consequences for natural populations interacting with cultured populations of local versus foreign origin? Genetic interactions with cultured, non-native populations almost certainly will be deleterious, but their frequency might be greatly reduced by physical, behavioral, or management isolating mechanisms. Genetic interactions with cultured populations of local origin should be less harmful per interaction, but the frequency of interactions might be greatly increased. The net effect on the wild population will be a function of both the frequency and severity of the interactions when they do occur, and this topic has not been treated rigorously in the literature.

- What are the genetic mechanisms involved in domestication? (see Araki et al. 2008). To what extent is domestication reversible, and on what time frames? What culture practices can effectively minimize effects of domestication?

- What is the reproductive success in the wild of individuals reared in culture? What are the long-term effects of supplementation on the ability of populations to sustain themselves in the wild?

- What is the relative importance of inbreeding depression and outbreeding depression, and how does this vary among species and among populations within species? 
A variety of methods can provide insight into these questions. Genomic and quantitative genetic studies will be feasible for some species. Ready availability of numerous, highly polymorphic molecular markers allows reliable parentage analysis of progeny, which provides high power to studies of reproductive success and selection differentials in the wild. Genomic approaches can identify genes that might respond to selection, inbreeding depression, and outbreeding depression, and changes in their population frequencies can be monitored. However, it should be recognized that many of these questions can only be answered with long-term studies, since many fitness effects will only become apparent over many generations.

\subsubsection{Climate Change}

Evidence is rapidly accumulating to demonstrate that global warming has caused genetic changes in animal species as diverse as birds, squirrels, and mosquitoes (Bradshaw and Holzapfel 2006). To date, the documented changes have primarily involved timing of seasonal events (e.g., reproduction or migration), although it is expected that further research will uncover morphological, behavioral, and physiological adaptations, such as increased thermal tolerance. The effects of climate on fish population dynamics has long been recognized (Cushing 1983; Tolimieri and Levin 2005), but only recently has attention focused on the likely future consequences of global warming (Overland and Wang 2007). Aquatic species have evolved mechanisms to allow persistence in variable environments, but long-term, directional changes (such as are predicted under many climate change scenarios) will represent a new type of challenge. Here are the some current and future research needs that would increase our understanding of this key topic.

- Document nature, extent, and rate of environmental changes expected to be associated with future climate change. This would involve translating general predictions from the most recent Intergovernmental Panel on Climate Change report (IPCC 2007) into more focused predictions for marine ecosystems.

- Identify key species and their vulnerable life stages that are most likely to be affected by global warming. A key element here will be integration of biological information for the species with physical information about their changing habitats.

- Evaluate capacity of the species to respond to environmental changes through phenotypic plasticity. Initially, such experiments can be conducted in the laboratory by exposing individuals from genetically uniform populations to different temperature environments. Ideally, these experiments would then be extended to the wild by transplanting related individuals into different environments and studying the range of their phenotypic responses, such as levels of expression at relevant genes, changes in correlated fitness traits, and their reproductive success.

- Evaluate the capability of the species to adapt to new environmental conditions. Can the species evolve fast enough to keep pace with the rate of environmental change? In the absence of experimental data for the species in question, insights can be obtained from literature surveys that show rates of evolutionary change typically 
found in natural populations (Hendry and Kinnison 1999), from long-term studies of evolution of quantitative traits in controlled environments, or from models based on empirical measures of genetic variation underlying fitness traits.

- Look for mismatches between anticipated magnitude and rate of change in the physical environment and the capacity for a plastic and/or an evolutionary response. These mismatches identify the species and life stages that are most likely to be strongly affected by global warming.

\subsection{Discussion and Conclusions}

Genetic methods have become indispensable to twenty-first-century fishery management, and their relative importance is likely to increase in the coming decades, particularly as genetic approaches become better integrated with more traditional ones. In this chapter we have considered only a fraction of the types of questions that can and will be addressed by genetic approaches, and we have chosen to focus on two areas: (1) questions that utilize neutral genetic markers and provide insights into population genetic processes that are relevant to conservation and management, and (2) questions that rely on methods that study traits under selection, which are more directly related to population fitness.

One general topic that should get more serious consideration in the future is the relationship between statistical significance and biological significance (Waples 1998; Hedrick 1999; Palsbøll et al. 2007). Although the traditional hypothesistesting framework has many advantages, it is safe to say that no aquatic population ever suffered any consequences directly as the result of a $P$-value associated with a statistical test. Rather, biological consequences depend on the magnitude and direction of an effect (the effect size). That is, it is not enough to determine that a (nonzero) effect can be detected; it is also important to determine how large the effect is, and what the biological consequences are for the species of interest. The importance of this point for identification of stocks and conservation units has been emphasized in the literature (Waples 1998; Palsbøll et al. 2007), but it applies more generally to the field of fishery management.

This is an exciting time for use of genetic methods in applied conservation, as a confluence of several factors has conspired to provide unprecedented opportunities. First, technical advances in the laboratory have uncovered an essentially unlimited number of highly variable genetic markers that can be utilized to study natural populations. These methods can extract DNA nonlethally from increasingly small amounts of biological material, which allows routine, non-invasive monitoring as well as retrospective analyses using historic samples (Schwartz et al. 2007). Second, numerous powerful analytical methods have been developed in the past decade that provide new opportunities to test hypotheses about contemporary evolutionary and ecological processes in populations (Pearse and Crandall 2004; Manel et al. 2005). Finally, in accordance with Moore's law, computational power continues to increase rapidly, and these increases have made feasible implementation of many of 
the new likelihood-based methods that are computationally demanding. We expect that incremental improvements in each of these areas will continue into the future, and these improvements will continue to refine and improve the applications of neutral genetic markers to fishery management.

Collectively, these and other advances have brought us to the point where it is feasible to contemplate the rigorous study of genetic variation at fitness-related traits in natural populations. These studies, however, are logistically challenging and resource-intensive, so in the near future they will be feasible only for a small fraction of marine species. It would be useful, therefore, if researchers working on marine species would coordinate selection of species on which to conduct quantitative genetic or population genomic studies. If this were done, it should be possible to arrange coverage across taxa in such a way to maximize the inferences that can be drawn from the studied species to the large majority that will not be studied directly. Both types of studies (whether they focus on neutral markers or genes under selection) could benefit from better integration with other types of information for the species in question (life history, physiology, behavior) and the environments they inhabit (current patterns, physical features of the habitat).

It is easy to see that whereas the ecological consequences of anthropogenic changes on aquatic populations have received a great deal of attention, the evolutionary consequences of these changes have been relatively neglected. It is much more difficult to determine exactly what these evolutionary consequences will be, and how important they will be to conservation and management. This is now an active area of research for terrestrial as well as marine species (e.g., a new journal, Evolutionary Applications, began publication in 2008), and we expect important new insights will emerge over the next decade.

Acknowledgments We thank Jeff Hard, Lorenz Hauser, Jeff Hutchings, Rick Methot, and Dave Philipp for useful discussions and suggestions.

\section{References}

Akey JM, Eberle MA, Rieder MJ, Carlson CS, Shriver MD, Nickerson DA, Kruglyak L (2004) Population history and natural selection shape patterns of genetic variation in 132 genes. PLoS Biol 2: e286

Anderson EC, Waples RS, Kalinowski S (2008) An improved method for predicting the accuracy of genetic stock identification. Can J Fish Aquat Sci 65:1475-1486

Anonymous (1992) Rio Declaration on Environment and Development. Environ Conserv 19:366-368

Anonymous (2007) Sustainable Marine Aquaculture: Fulfilling the Promise; Managing the Risks. Report of the Marine Aquaculture Task Force, January 2007. Pew Charitable Trust. Available from: http://pewtrusts.com/pdf/Sustainable_Marine_Aquaculture_final_1_07.pdf

Araki H, Berejikian BA, Ford MJ, Blouin M (2008) Fitness of hatchery-reared salmonids in the wild. Evol Appl 1:342-355

Avise JC, Jones AG, Walker D, Dewoody JA (2002) Genetic mating systems and reproductive natural histories of fishes: lessons for ecology and evolution. Annu Rev Genet 36:19-45 
Baker CS, Cooke JG, Lavery S, Dalebout ML, Ma Y-U, Funahashi N, Carraher C, Brownell RL (2007) Estimating the number of whales entering trade using DNA profiling and capturerecapture analysis of market products. Mol Ecol 16:2617-2626

Beaumont MA (2005) Adaptation and speciation: what can F-st tell us? Trends Ecol Evol 20:435-440

Bernatchez L, Landry C (2003) MHC studies in nonmodel vertebrates: what have we learned about natural selection in 15 years? J Evol Biol 16:363-377

Bonin A, Bellemain E, Eidesen PB, Pompanon F, Brochmann C, Taberlet P (2004) How to track and assess genotyping errors in population genetics studies. Mol Ecol 13:3261-3273

Bradshaw WE, Holzapfel CM (2006) Climate change - evolutionary response to rapid climate change. Science 312:1477-1478

Busack CA, Currens KP (1995) Genetic risks and hazards in hatchery operations: fundamental concepts and issues. Am Fish Soc Symp 15:71-80

Cadrin SX, Friedland KD, Waldman JR (eds) (2005) Stock identification methods: applications to fishery science. Elsevier Academic Press, Amsterdam

Carvalho GR, Hauser L (1994) Molecular genetics and the stock concept in fisheries. Rev Fish Biol Fish 4:326-350

Carvalho GR, Hauser L (1998) Advances in the molecular analysis of fish population structure. Ital J Zool 65:21-33

Cushing DH (1983) Climate and Fisheries. Academic, London

Danzmann RG, Gharbi K (2001) Gene mapping in fishes: a means to an end. Genetica 111:3-23

De Kovel CGF (2006) The power of allele frequency comparisons to detect the footprint of selection in natural and experimental situations. Genet Select Evol 38:3-23

DeYoung RW, Honeycutt RL (2005) The molecular toolbox: Genetic techniques in wildlife ecology and management. J Wildl Manage 69:1362-1384

Dieckmann U, Heino M (2007) Probabilistic maturation reaction norms; their history, strengths, and limitations. Mar Ecol Prog Ser 335:249-251

Emery AM, Wilson IJ, Craig S, Boyle PR, Noble LR (2001) Assignment of paternity groups without access to parental genotypes: multiple mating and developmental plasticity in squid. Mol Ecol 10:1265-1278

Falconer DS, Mackay TFC (1996) Introduction to Quantitative Genetics. Prentice Hall, Harlow, England, pp 464

Falush D, Stephens M, Pritchard JK (2003) Inference of population structure using multilocus genotype data: Linked loci and correlated allele frequencies. Genetics 164:1567-1587

FAO (2006) State of world aquaculture. FAO Fisheries Technical Paper 500. Food and Agriculture Organization of the United Nations. Rome

Frankham R (1995) Effective population size/adult population size ratios in wildlife: a review. Genet Res 66:95-107

Fraser D (2008) How well can captive breeding programs conserve biodiversity? A review of salmonids. Evol Appl 1:535-586

Galindo HM, Olson DB, Palumbi SR (2006) Seascape genetics: a coupled oceanographic-genetic model predicts population structure of Caribbean corals. Curr Biol 16:1622-1626

Garant D, Dodson JJ, Bernatchez L (2003) Differential reproductive success and heritability of alternative reproductive tactics in wild Atlantic salmon (Salmo salar L.). Evolution 57:1133-1141

Garrigan D, Hedrick PW (2003) Perspective: Detecting adaptive molecular polymorphism: lessons from the MHC. Evolution 57:1707-1722

Gjedrem T (2000) Genetic improvement of cold-water fish species. Aquat Res 31:25-33

Goetz WF, MacKenzie S (2008) Functional genomics with microarrays in fish biology and fisheries. Fish and Fisheries 9:378-395

Grift RE, Rijnsdorp AD, Barot S, Heino M, Dieckmann U (2003) Fisheries-induced trends in reaction norms for maturation in North Sea plaice. Mar Ecol Prog Ser 257:247-257

Hard, JJ (2004) Evolution of chinook salmon life history under size-selective harvest. In: Hendry A, Stearns S (eds) Evolution illuminated: salmon and their relatives. Oxford University Press, New York, pp. 315-337 
Hastings A (1993) Complex interactions between dispersal and dynamics: lessons from coupled logistic equations. Ecology 74:1362-1372

Hauser L, Adcock GJ, Smith PJ, Bernal Ramirez JH, Carvalho GR (2002) Loss of microsatellite diversity and low effective population size in an overexploited population of New Zealand snapper (Pagrus auratus). Proc Nat Acad Sci USA 99:11742-11747

Hauser L, Carvalho GR (2008) Paradigm shifts in marine fisheries genetics: ugly hypotheses slain by beautiful facts. Fish and Fisheries 9:333-362

Hedgecock D (1994) Does variance in reproductive success limit effective population sizes of marine organisms? In: Beaumont AR (ed) Genetics and evolution of aquatic organisms. Chapman \& Hall, London, pp. 122-134

Hedrick PW (1999) Perspective: highly variable loci and their interpretation in evolution and conservation. Evolution 53:313-318

Hendry AP Kinnison MT (1999) The pace of modern life: measuring rates of contemporary microevolution. Evolution 53:637-1653

Hoarau G, Boon E, Jongma1 DN, Ferber S, Palsson J, Van der Veer HW, Rijnsdorp AD, Stam WT, Olsen JL 2005 Low effective population size and evidence for inbreeding in an overexploited flatfish, plaice (Pleuronectes platessa L.) Proc R Soc B 272:497-503

Ihssen PE, Bodre HE, Casselman JM, McGlade JM, Payne NR, Utter F (1981) Stock identification: materials and methods. Can J Fish Aquat Sci 38:1838-1855

IPCC (Intergovernmental Panel on Climate Change) (2007) Climate change 2007: 4th Assessment Report, http://www.ipcc.ch/

Johnson MS, Wernham J (1999) Temporal variation of recruits as a basis of ephemeral genetic heterogeneity in the western rock lobster Panulirus cygnus. Mar Biol 135:133-139

Kawecki TJ, Ebert D (2004) Conceptual issues in local adaptation. Ecol Lett 7:1225-1241

Keller LF, Grant PR, Grant BR, Petren K (2001) Heritability of morphological traits in Darwin's Finches: misidentified paternity and maternal effects. Heredity 87:325-336

Kimura M, Crow JF (1964) The number of alleles that can be maintained in a finite population. Genetics 49:725-738

Kraak SBM (2007) Does the probabilistic maturation reaction norm approach distentangle phenotypic plasticity from genetic change? Mar Ecol Prog Ser 335:295-300

Law R (2000) Fishing, selection, and phenotypic evolution. ICES J Mar Sci 57:659-668

Law R (2007) Fisheries-induced evolution; present status and future directions. Mar Ecol Prog Ser 335:271-277

Leber KM, Kitada S, Blankenship HL, Svåsand T (eds) (2004) Stock enhancement and sea ranching. Blackwell, Oxford, pp. 562

Lubchenco J, Palumbi SR, Gaines SD, Andelman S (2003) Plugging a hole in the ocean: the emerging science of marine reserves. Ecol Appl 13: S3-S7

Luikart G, England PR, Tallmon D, Jordan S, Taberlet P (2003) The power and promise of population genomics: From genotyping to genome typing. Nat Rev Genet 4:981-994

Lynch M, Walsh B (1998) Genetics and Analysis of Quantitative Traits. Sinauer, Sunderland, MA, 980pp

Manel S, Gaggiotti O, Waples RS (2005) Assignment methods: matching biological questions with appropriate techniques. Trends Ecol Evol 20:136-142

McElhany P, Ruckelshaus MH, Ford MJ, Wainwright TC, Bjorkstedt EP (2000) Viable salmon populations and the recovery of evolutionarily significant units. Northwest Fisheries Science Center, Seattle, 156pp. NOAA Technical Memorandum, NMFS-NWFSC-58 http://www. nwfsc.noaa.gov/publications/

McGuigan K (2006) Studying phenotypic evolution using multivariate quantitative genetics. Mol Ecol 15:883-896

Mitchell-Olds T, Schmitt J (2006) Genetic mechanisms and evolutionary significance of natural variation in Arabidopsis. Nature 441:947-952

Mooney HA (1998) Ecosystem management for sustainable marine fisheries. Ecol Appl 8: S1-S1

Morita K, Fukuwaka MA (2006) Does size matter most? The effect of growth history on probabilistic reaction norm for salmon maturation. Evol 60:1516-1521 
Naish KA, Hard JJ (2008) Bridging the gap between the genotype and the phenotype: linking genetic variation, selection and adaptation in fishes. Fish and Fisheries 9:396-422

Naish KA, Taylor J, Levin P, Quinn TP, Winton JR, Huppert D, Hilborn R (2008) An evaluation of the effects of conservation and fishery enhancement hatcheries on wild populations of salmon. Adv Mar Biol 53:61-194

Naylor RL, Hindar K, Fleming IA, Goldberg R, Mangel M, Williams S, Volpe J, Whoriskey F, Eagle J, Kelso D (2005) Fugitive salmon: assessing risks of escaped farmed fish from aquaculture. Bioscience 55:427-437

Niemi G, Wardrop D, Brooks R, Anderson S, Brady V, Paerl H, Rakocinski C, Brouwer M, Levinson B, McDonald M (2004) Rationale for a new generation of indicators for coastal waters. Environ Health Perspect 112:979-986

Nunney L (1993) The influence of mating system and overlapping generations on effective population size. Evolution 47:1329-1341

Olsen JB, Bentzen P, Banks MA, Shaklee JB, Young S (2000) Microsatellites reveal population identity of individual pink salmon to allow supportive breeding of a population at risk of extinction. Trans Am Fish Soc 129:232-242

Olsen EM, Heino M, Lilly GR, Morgan MJ, Brattey J, Ernande B, Dieckmann U (2004) Maturation trends suggestive of rapid evolution preceded collapse of northern cod. Nature 428:932-935

Olsen EM, Lilly GR, Heino M, Morgan M J, Brattey J, Dieckmann U (2005) Assessing changes in age and size at maturation in collapsing populations of Atlantic cod (Gadus morhua). Can J Fish Aquat Sci 62:811-823

Overland JE, Wang M (2007) Future climate of the North Pacific Ocean. EOS 88:178-180

Palsbøll PJ, Bérubé M, Allendorf FW (2007) Identification of management units using population genetic data. Trends Ecol Evol 22:11-16

Paetkau D, Slade R, Burden M, Estoup A (2004) Genetic assignment methods for the direct, real-time estimation of migration rate: a simulation-based exploration of accuracy and power. Mol Ecol 13:55-65

Pearse DE, Crandall KA (2004) Beyond Fst: population genetic analysis for conservation. Cons Genet 5:585-602

Pella J, Milner GB (1987) Use of genetic marks in stock composition analysis. In: Ryman N, and Utter F (eds) Population genetics \& fishery management. University of Washington Press, Seattle, WA, pp. 247-276

Pella J, Masuda M (2006) The Gibbs and split-merge sampler for population mixture analysis from genetic data with incomplete baselines. Can J Fish Aquat Sci 63:576-596

Philipp DP, Cooke SJ, Clausen JE, Koppelman JB, Suski CD, Burkett DP (in press) Selection for vulnerability to angling in largemouth bass. Trans Am Fish Soc (was cited in the text as a personal communication)

Pigliucci M (2005) Evolution of phenotypic plasticity: where are we going now? Trends Ecol Evol 20:481

Pompanon F, Bonin A, Bellemain E, Taberlet P (2005) Genotyping errors: causes, consequences and solutions. Nat Rev Genet 6:847-859

Pritchard JK, Stephens M, Donnelly P (2000) Inference of population structure using multilocus genotype data. Genetics 155:945-959

Pujolar JM, Maes GE, Volckaert FAM (2006) Genetic patchiness among recruits in the European eel Anguilla anguilla. Mar Ecol Prog Ser 307:209-217

Purcell MK, Nichols KM, Winton JR, Kurath G, Thorgaard GH, Wheeler P, Hansen JD, Herwig RP, Park LK (2006) Comprehensive gene expression profiling following DNA vaccination of rainbow trout against infectious hematopoietic necrosis virus. Mol Immunol 43:2089-2106

Quinn TP, Hodgson S, Flynn L, Hilborn R, Rogers DE (2007) Directional selection by fisheries and the timing of sockeye salmon (Oncorhynchus nerka) migrations. Ecol Appl 17:731-739

Restropo VR (ed) (1999) Providing scientific advice to implement the precautionary approach under the Magnuson-Stevens Fishery Conservation and Management Act. Proceedings of the fifth national NMFS stock assessment workshop. US Department of Commerce, NOAA Tech. Memo. NMFS F/SPO-40, 161p 
Ricker WE (1981) Changes in the average size and average age of Pacific salmon. Can J Fish Aquat Sci 38:1636-1656

Ricker WE (1995) Trends in the average size of Pacific salmon in Canadian catches. In: Beamish RJ (ed.) Climate change and northern fish populations, vol 121. Canadian Special Publication in Fisheries and Aquatic Sciences 121, Ottawa, pp. 593-602

Roberge C, Einum S, Guderley H, Bernatchez L (2006) Rapid parallel evolutionary changes of gene transcription profiles in farmed Atlantic salmon. Mol Ecol 15:9-20

Ryman N, Utter F (eds) (1987) Population genetics \& fishery management. University of Washington Press, Seattle, WA

Ryman N, Utter F, Laikre L (1995) Protection of intraspecific biodiversity of exploited fishes. Rev Fish Biol Fish 5:417-446

Schadt EE, Lamb J, Yang X, Zhu J, Edwards S, GuhaThakurta D, Sieberts SK, Monks S, Reitman M, Zhang C, Lum PY, Leonardson A, Thieringer R, Metzger JM, Yang L, Castle J, Zhu H, Kash SF, Drake TA, Sachs A, Lusis AJ (2005) An integrative genomics approach to infer causal associations between gene expression and disease. Nat Genet 37:710-717

Schlotterer C, Neumeier H, Sousa C, Nolte V (2006) Highly structured Asian Drosophila melanogaster populations: A new tool for hitchhiking mapping? Genetics 172:287-292

Schwartz MK, Luikart G, Waples RS (2007). Genetic monitoring: a promising tool for conservation and management. Trends Ecol Evol 22:25-33

Selkoe KA, Gaines SD, Caselle JE, Warner RR (2006) Current shifts and kin aggregation explain genetic patchiness in fish recruits. Ecology 87:3082-3094

Selkoe KA, Henzler CM, Gaines SD (2008) Seascape genetics and the spatial ecology of marine populations. Fish and Fisheries 9:363-377

Shaklee JB, Beacham TD, Seeb L, White BA (1999) Managing fisheries using genetic data: case studies from four species of Pacific Salmon. Fish Res 43:45-78

Simon RC, Larkin PA (eds) (1972) The stock concept in Pacific salmon. HR MacMillan Lectures in Fisheries, University of British Columbia, Vancouver

Smith TB, Bernatchez L (2008) Evolutionary change in human-altered environments. Mol Ecol $17: 1-499$

Smouse PE, Waples RS, Tworek JA (1990) A mixed fishery model for use with incomplete source population data. Can J Fish Aquat Sci 47:620-634

Stearns SC, Magwene P (2003) The naturalist in a world of genomics. Am Nat 161:171-180

Storz JF (2005) Using genome scans of DNA polymorphism to infer adaptive population divergence. Mol Ecol 14:671-688

Suttle CA (2005) Viruses in the sea. Nature 437:356-361

Tolimieri N, Levin PS (2005) The roles of fishing and climate in the population dynamics of bocaccio rockfish. Ecol Appl 15:458-468

Trippel EA (1998). Egg size and viability and seasonal offspring production of young Atlantic cod. Trans Am Fish Soc 127:339-359

Turner TF, Wares JP Gold JR (2002) Genetic effective size is three order of magnitude smaller than adults census size in an abundant, estuarine-dependant marine fish (Scianops ocellatus). Genetics 162:1329-1339

Vasemägi A, Primmer CR (2005) Challenges for identifying functionally important genetic variation: the promise of combining complementary research strategies. Mol Ecol 14:3623-3642

Verardi A, Lucchini V, Randi E (2006) Detecting introgressive hybridization between free-ranging domestic dogs and wild wolves (Canis lupus) by admixture linkage disequilibrium analysis. Mol Ecol 15:2845-2855

von Schalburg KR, Rise ML, Brown GD, Davidson WS, Koop BF (2005) A comprehensive survey of the genes involved in maturation and development of the rainbow trout ovary. Biol Reprod 72:687-699

Waldman JR (2005) Definition of stock: an evolving concept. In: Cadrin SX, Friedland KD, Waldman JR (eds) Stock identification methods: applications to fishery science. Elsevier Academic Press, Amsterdam, pp. 7-16 
Walsh MR. Munch SB, Chiba S, Conover DO (2006) Maladaptive changes in multiple traits caused by fishing: impediments to population recovery Ecol Lett 9:142-148

Waples R (1998) Separating the wheat from the chaff: patterns of genetic differentiation in high gene flow species. J Hered 89:438-450

Waples RS (1990) Conservation genetics of Pacific salmon. II. Effective population-size and the rate of loss of genetic-variability. J Hered 81:267-276

Waples RS, Drake J (2004) Risk-benefit considerations for marine stock enhancement: a Pacific salmon perspective. In: Leber KM, Kitada S, Blankenship HL, Svåsand T (eds) Stock enhancement and sea ranching: developments, pitfalls and opportunities, 2nd edn. Blackwell, Oxford, pp. 260-306

Waples RS, Gaggiotti O (2006) What is a population? An empirical evaluation of some genetic methods for identifying the number of gene pools and their degree of connectivity. Mol Ecol 15:1419-1439

Waples RS, Punt AE, Cope J (2008) Integrating genetic data into fisheries management: how can we do it better? Fish and Fisheries 9:423-449

Ward RD, Woodward M, Skibinski DOF (1994) A comparison of genetic diversity levels in marine, freshwater, and anadromous fishes. J Fish Biol 44:213-232

Ward RD (2006) The importance of identifying spatial population structure in restocking and stock enhancement programmes. Fish Res 80:9-18 